\title{
Heart attacks in systemic scleroderma: about a case in Conakry
}

Djibril Sylla ${ }^{1 *}$, Amadou Kake², Ibrahima Sory2 Sylla², Aly Samoura ${ }^{2}$, Abdoulaye Camara², Ibrahima Sory Barry ${ }^{2}$, Ibrahima Camara ${ }^{3}$, Boh Fanta Diane ${ }^{5}$, Mariam Beavogui ${ }^{2}$ and Mamadou Dadhi Balde ${ }^{2}$

*Correspondence: docdjibril@gmail.com

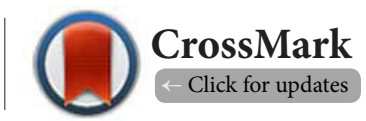

'Department of Medical and Surgical Emergencies of Donka National Hospital, Guinea.

${ }^{2}$ Cardiac Service of Ignace Deen National Hospital, Guinea.

${ }^{3}$ Department of Diabetology-Endocrinology and Metabolic Diseases of Donka National Hospital, Guinea.

${ }^{4}$ Department of Infectious and Tropical Diseases at Donka National Hospital, Guinea.

${ }^{5}$ Dermatology Department of Donka National Hospital, Guinea.

\begin{abstract}
Summary: The objective of this study was to describe the cardiac manifestations during systemic scleroderma in Conakry and the therapeutic management.

Observation: 49-year-old female patient, admitted to the Medico-Surgical Emergency Department of Donka Hospital and University for chest pain, dry cough, osteo-articular pain, physical asthenia; evolution of symptoms for two weeks, no history of known cardiovascular disease and no cardiovascular risk factor. On physical examination, we have: $\mathrm{TA}=130 / 80 \mathrm{mmHg}$, heart rate at 110 beats $/$ minute, height $1.78 \mathrm{~cm}$, weight $65 \mathrm{~kg}$ (BMI: $20.56 \mathrm{~kg} / \mathrm{m}^{2}$ ). There was also a decrease in heart sounds, no rhythm disorder or deformation of the chest, no scar on the thorax, temperature at $37.6^{\circ} \mathrm{C}$, axial deformation of the fingers of both hands with hypochromia, hard, localized at the level of small joints.

Conclusion: Systemic scleroderma is an autoimmune disease that is more common in women than in men. His diagnosis is clinical, immunological and completed by the classification criteria. The functional or vital prognosis can be put into play especially in case of heart attack as was the case in our patient. Corticotherapy opens a window of hope despite the fact that treatment is difficult.
\end{abstract}

Keywords: Scleroderma, cardiac involvement, Conakry, young subject

\section{Introduction}

Systemic scleroderma is a rare autoimmune disease characterized by vascular involvement of the connective tissue (involvement of small vessels: arterioles and capillaries) responsible for systemic fibrosis that varies from person to person (digestive, cardiac, pulmonary, renal, articular involvement) [1].

The prevalence is estimated at about 1-9/100,000 for localized scleroderma and 1/6500 adults for systemic scleroderma, the disease is most prevalent in women, it usually occurs between 40 and 50 years of age and rarely affects children [1].

Cardiac involvement occurs in $70 \%$ of cases during the first five years of the disease [2].

\section{Observation}

49-year-old female patient admitted to the Medico-Surgical
Emergency Department of the Donka Hospital and University for chest pain, dry cough, osteo-articular pain, physical asthenia; evolution of symptoms for two weeks, no history of known cardiovascular disease and no cardiovascular risk factor. On physical examination we noted: $\mathrm{TA}=130 / 80 \mathrm{mmHg}$ heart rate at 110 beats/minute, height $1.78 \mathrm{~cm}$, weight $65 \mathrm{~kg}$ (BMI: 20.56 $\mathrm{kg} / \mathrm{m}^{2}$ ). There was also a decrease in heart sounds, no rhythm disorder or deformation of the chest, no scar on the thorax, the temperature at $37.6^{\circ} \mathrm{C}$, there was axial deformation of the fingers of both hands with hypochromia, hard, localized at the level of small joints (Figure 1).

The electrocardiogram recorded a regular sinus rhythm at 68 cycles/min, and prior extended negative T waves with left ventricular electrical hypertrophy (Figure 2).

The frontal chest $\mathrm{X}$-ray revealed an accentuation of the

(C) 2019 Sylla et al; licensee Herbert Publications Ltd. This is an Open Access article distributed under the terms of Creative Commons Attribution License (http://creativecommons.org/licenses/by/3.0). This permits unrestricted use, distribution, and reproduction in any medium, provided the original work is properly cited. 


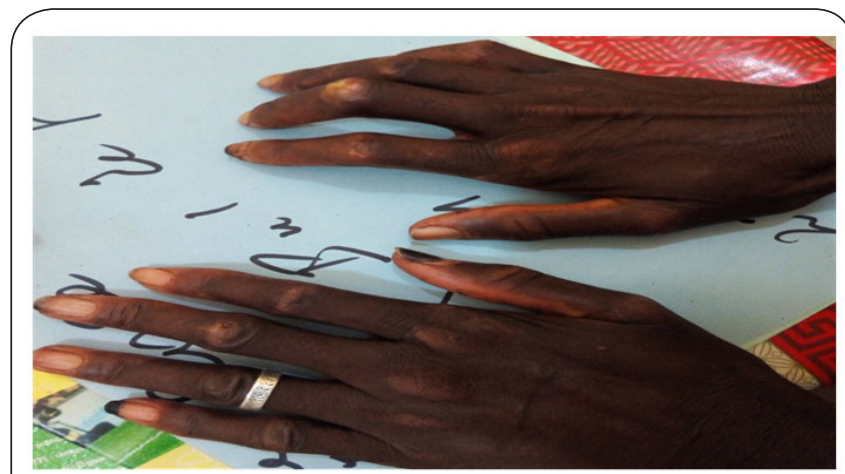

Figure 1. Axial deformation of the fingers with localized hardening of the skin of the hands.

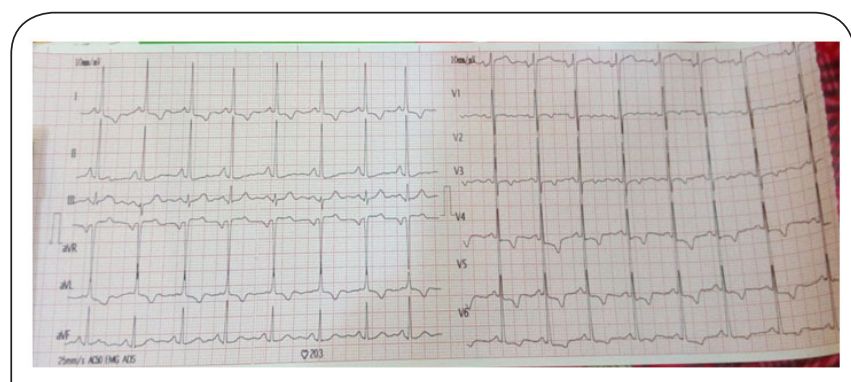

Figure 2. Regular sinus rhythm at 68 cycles/min, extended front T-waves extended with left ventricular hypertrophy.

broncho-vascular pattern, a diffuse heterogeneous heterameric opacity with bilateral hilar widening, and cardiomegaly with a cardiothoracic index of 0.69 (Figure 3).

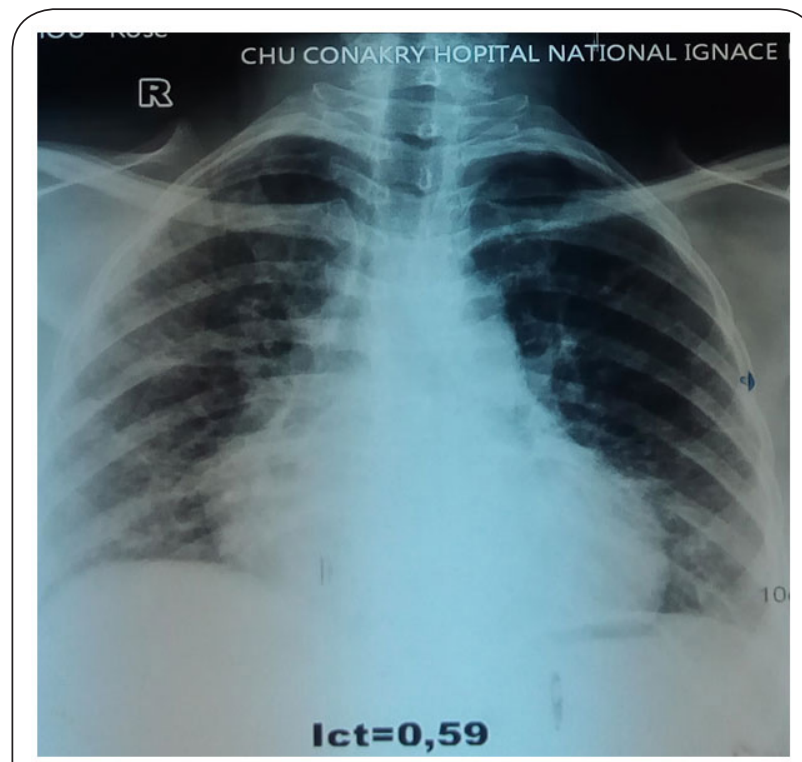

Figure 3. Digitized chest X-ray; highlights an accentuation of the bronchovascular framework, bilateral hilar widening, cardiomegaly with a cardiothoracic ratio at 0.69.
X-rays of the hands, wrists, and feet showed a pinch with osteocondensations of inter-carpal, inter-tarsal, carpo-metacarpal, tarso-metatarsal, metacarpophalangeal, metatarsophalangeal, and inter-phalangeal joint space advocating for arthritis (Figure 4).

Cardiac Doppler ultrasound revealed a circumferential circumferential pericardial effusion of moderate to moderate abundance $(11 \mathrm{~mm}$ to $18 \mathrm{~mm})$ in anteroposterior without fibrin network (Figure 5).

Biology: Sclero-70 greater than $9 U$ (normal value less than

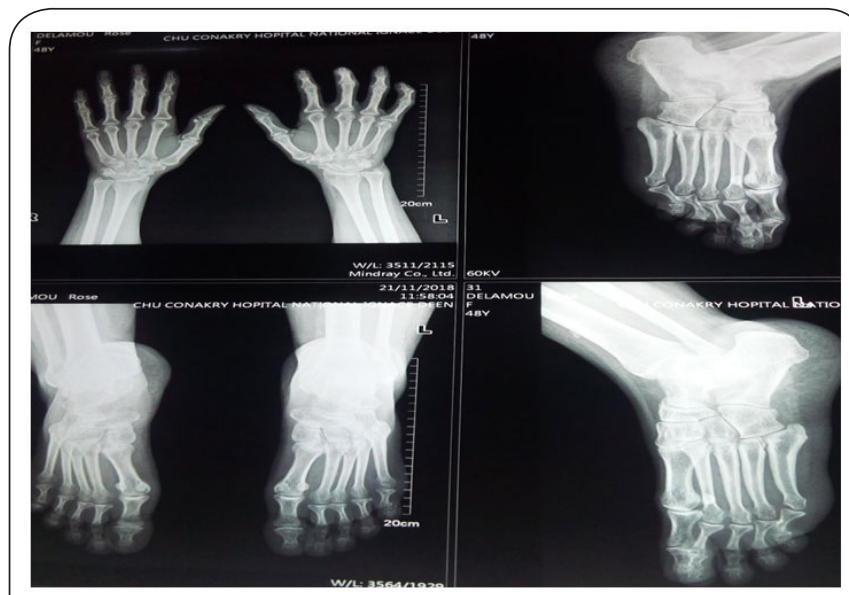

Figure 4. X-ray of the hands and wrist plus feet showing a pinch.

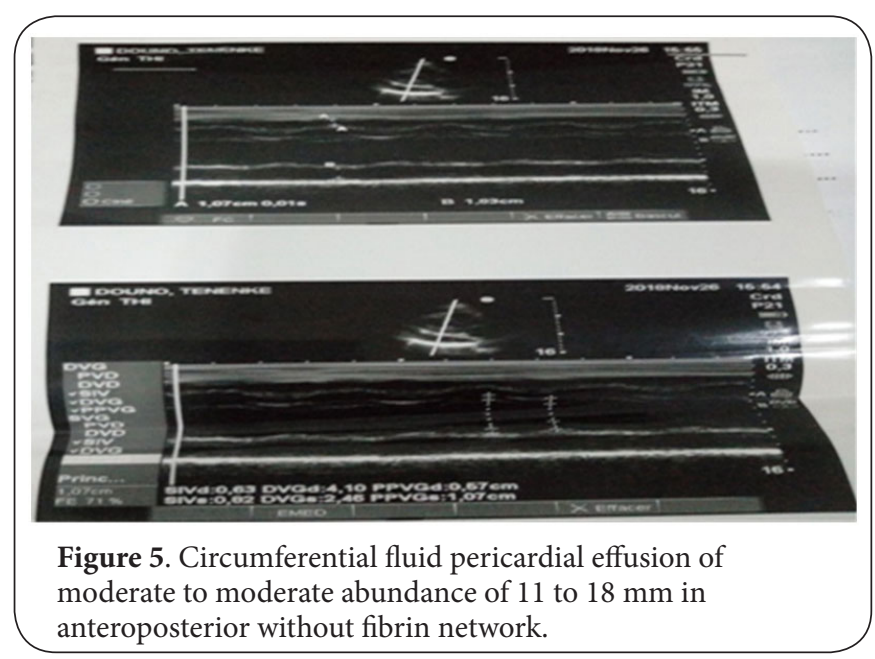

$0.9 \mathrm{U})$, rheumatoid factor was negative, Hemoglobin $=13.3 \mathrm{~g} /$ $\mathrm{dl}$, neutrophils $=49.7 \%$, eosinophilic polynuclear $=3.5 \%$, polymorphonuclear basophilic $=0.9 \%$, hyper lymphocytosis $=41.1 \%$, hyper monocytosis $=4.8 \%$, platelets $=191 \mathrm{~g} / \mathrm{l}$, blood lonogram (Natrium $=5.9 \mathrm{mmol} / \mathrm{l}$, potassium $=129 \mathrm{mml} / \mathrm{l}$, calcium $=2.36$ $\mathrm{mmol} / \mathrm{l}, \mathrm{Cl}-=98 \mathrm{mmol} / \mathrm{l} \mathrm{HCO}-3=26 \mathrm{mmol} / \mathrm{l}$.

\section{Discussion}

Several works have been devoted to the cardiac lesions of 
scleroderma whose main mechanism is a disruption of the functioning of the cardiac muscle by a bad vascular irrigation. It remains for a long time without or with few clinical symptoms that may cause shortness of breath and/or chest pain, see pericarditis [3].

We report the case of a 49-year-old woman who developed systemic scleroderma complicated by anteroposterior pericardial effusion. This condition mainly affects women (4 women to 1 man approximately), and usually occurs between 40 and 50 years. Scleroderma can occur exceptionally in children. It affects all populations in principle, but is more common in people exposed to certain industrial chemicals or in miners [4]. In case of scleroderma, collagen is produced in excess and accumulates in the skin and various organs. This is called fibrosis, in reference to the fibrous and rigid aspect that gives excess collagen to the affected organs, including the skin. Fibrosis can also thicken the walls of some vessels to the point where it eventually clogs them and prevents blood from circulating. In particular, these lesions threaten the internal organs (heart, kidneys) by partially depriving them of oxygen and the nutrients normally provided by the blood, and a rare disease [4].

Our case is a perfect illustration of this nosological rarity. Predisposing factors are found in the majority of cases, including certain industrial chemicals or juveniles, and gender [5].

In our case, pericardial effusion was clinically manifested by chest pain, cough, fever, physical asthenia, and bone manifestation was osteoarticular pain and axial deformity of the fingers. Indeed, autoptic series show that nearly $80 \%$ of patients may have histological cardiac lesions [3]. Pericardial involvement is very common in autoptic studies in 33 to $72 \%$ of patients, whereas it is clinically evident in only 11 to $41 \%$. Tamponade is exceptional. In cardiac ultrasonography, the prevalence of pericardial effusion varies between 11 and $41 \%$, but most recent studies give a figure between 11 and $18 \%$. Most often, these are fortuitous ultrasound findings, without clinical translation [1]. Our clinical case is an example of this as shown (Figure 3): Circumferential fluidic pericardial effusion of moderate to moderate abundance $(11 \mathrm{~mm}$ to $18 \mathrm{~mm}$ ) in anteroposterior without fibrin network. Normal sized heart chambers free of thrombus. Good bi-ventricular systolic function $\mathrm{FE}=71 \%$ in Teicholz, TAPSE $=18 \mathrm{~mm}$. In our case the treatment was: administration of calcium + vit D 1 $\mathrm{g} /$ day and deparasitant based on albendazol $400 \mathrm{mg}$ per day for three days, Colchicine $20 \mathrm{mg}$ at the dose of $60 \mathrm{mg}$ per day and divided in three days, the patient benefited from cortisone (diprostene) infiltration at four joints (two wrists and two ankles). After one week of treatment there was a clear remission of signs that eventually disappeared after 6 months of evolution.

\section{Conclusion}

Systemic scleroderma is a more common connective tissue disease in women than in men.

His diagnosis is clinical, immunological and completed by the classification criteria.

The functional or vital prognosis can be put into play especially in cases of cardiac damage as was the case in our patient. Corticotherapy opens a window of hope despite the fact that treatment is difficult.

\section{Competing interests}

The authors declare that they have no competing interests.

Authors' contributions

\begin{tabular}{|l|c|c|c|c|c|c|c|c|c|c|}
\hline Authors' contributions & DS & AK & ISS & AS & AC & ISB & IC & BFD & MB & MDB \\
\hline Research concept and design & $\checkmark$ & $\checkmark$ & $\checkmark$ & $\checkmark$ & $\checkmark$ & $\checkmark$ & $\checkmark$ & $\checkmark$ & $\checkmark$ & $\checkmark$ \\
\hline Collection and/or assembly of data & $\checkmark$ & $\checkmark$ & $\checkmark$ & $\checkmark$ & $\checkmark$ & $\checkmark$ & $\checkmark$ & $\checkmark$ & $\checkmark$ & $\checkmark$ \\
\hline Data analysis and interpretation & $\checkmark$ & $\checkmark$ & $\checkmark$ & $\checkmark$ & $\checkmark$ & $\checkmark$ & $\checkmark$ & $\checkmark$ & $\checkmark$ & $\checkmark$ \\
\hline Writing the article & $\checkmark$ & $\checkmark$ & $\checkmark$ & $\checkmark$ & $\checkmark$ & $\checkmark$ & $\checkmark$ & $\checkmark$ & $\checkmark$ & $\checkmark$ \\
\hline Critical revision of the article & $\checkmark$ & $\checkmark$ & $\checkmark$ & $\checkmark$ & $\checkmark$ & $\checkmark$ & $\checkmark$ & $\checkmark$ & $\checkmark$ & $\checkmark$ \\
\hline Final approval of article & $\checkmark$ & $\checkmark$ & $\checkmark$ & $\checkmark$ & $\checkmark$ & $\checkmark$ & $\checkmark$ & $\checkmark$ & $\checkmark$ & $\checkmark$ \\
\hline Statistical analysis & $\checkmark$ & $\checkmark$ & $\checkmark$ & $\checkmark$ & $\checkmark$ & $\checkmark$ & $\checkmark$ & $\checkmark$ & $\checkmark$ & $\checkmark$ \\
\hline
\end{tabular}

Acknowledgments

We would like to thank all the doctors and personal surgeons of the emergency department of Donka National Hospital.

\section{Publication history}

EIC: Fabio Angeli, University of Perugia, Italy.

Received: 15-Jan-2019 Final Revised: 20-Feb-2019

Accepted: 22-Feb-2019 Published: 15-Mar-2019

\section{References}

1. Sclérodermie systémique - Focus Handicap/Encyclopédie Orphanet du Handicap. 2018. I Pdf
2. David Launay et coll. Service de médecine interne, Centre national de référence des atteintes vasculaires de la sclérodermie, Hôpital Claude-Hu- 
Sylla et al. Internal Medicine Inside 2019,

http://www.hoajonline.com/journals/pdf/2052-6954-7-1.pdf

riez, CHRU, 59037 Lille Cedex

d-launay@chru-lille.fr Service de cardiologie C, Hôpital cardiologique, CHRU, 59037 Lille Cedex Service de radiologie cardiovasculaire, Hôpital Cardiologique, CHRU, 59037 Lille Cedex 2006

3. WWW1.actelion.fr complication et évolution de la sclérodermie systémique France SAS/ACT-008-09/18

4. Encyclopédie Orphanet Grand Public. Maladies Rares Info Services 0156 5381 36. 2007. | Pdf

5. LM Diaby1, A Sanogo1, AST Kane1, AS Maiga1, L Diallo1, S KonAe2, Y Camara1, O Diawara5, L Diarra3

\section{Citation:}

Sylla D, Kaké A, Sylla IS, Samoura A, Camara A, Barry

IS, Camara I, Diane BF, Beavogui M and Balde MD.

Heart attacks in systemic scleroderma: about a case in

Conakry. Intern Med Inside. 2019; 7:1.

http://dx.doi.org/10.7243/2052-6954-7-1 